\title{
The effect of insect sex life on the world economy; Evasion of mating disruption with sex pheromones in insect pest control
}

https://doi.org/10.51167/ice00001

\author{
Arnon Shani \\ Department of Chemistry, Ben-Gurion University of the Negev, Beer Sheva \\ Email: ashani@bgu.ac.il
}

\begin{abstract}
This article deals with pheromones, animal chemical communication materials, based on popular public lectures, on the one hand, and chemical and biological information on the other. The last part of the article was written recently as the result of fresh news from the field, which affirmed my working hypothesis regarding evasion of mating disruption. I have chosen to present the topic through a Q\&A, focusing on the topics that are often raised by listeners or other interested parties.
\end{abstract}

Q: There are two titles and so there are two questions: Is the first title a publicity stunt or is there something real hidden behind it? The second relates to the application. Could you please elaborate?

A: As for the first one, the relationship is very close and this is the heart of the article. Every word is essential. The second one is the highlight of my studies and it will be explained in the last part of the article.

Q: So, what is the connection between insect sex life and the world economy?

A: The connection is in pest control in general, and in agriculture, in particular.

Q: How are these materials used for pesticides?

A: To understand this, you must understand the significance of chemical communication between animals, in general, and insects, in particular, that are the major pests in agriculture.
Q: What does "chemical communication" mean?

A: Chemical communication is part of the information transfer system between animals, including humans. As is well known, there are five senses for transferring information between animals (also between animals and plants). Two senses are physical senses - the sense of hearing and the sense of touch. Two senses are chemical senses - the sense of taste and sense of smell, based on the interaction of molecules with receptors in the corresponding organs (mouth, tongue; nose). The sense of vision is a combination of a physical process (in the beginning) and a chemical process (thereafter).

Q: Is it possible to place all the communication chemicals in one group, or are there different categories?

A: All chemicals used to transmit information are called semiochemicals or infochemicals.

Prof. Arnon Shani is an Emeritus Professor in the Chemistry Department at Ben-Gurion University of the Negev. He received his MSc degree at the Hebrew University of Jerusalem with Prof. A. D. Bergman and his PhD at the Weizmann Institute with Prof. P. Sondheimer. After a postdoc in Chicago University, he joined the research group of Prof. Rafael Meschulam's at the Jerusalem School of Pharmacy. In 1968, he joined the four founders of the Chemistry Department at the five-years-old Institute of Higher Education in the Negev, which later became Ben-Gurion University of the Negev. Arnon held many senior positions at Ben-Gurion University, as well as nationally and internationally. He served as President of the ICS from 1997-2003 and was appointed an Honorable Member of the ICS in 2014.

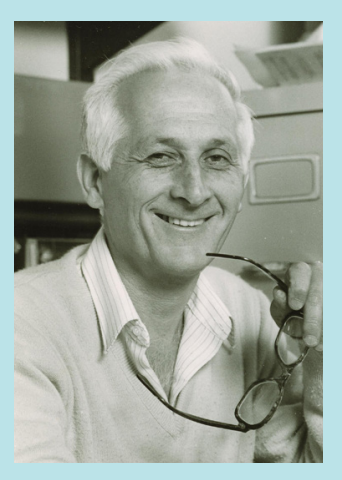


Q: We know ingredients that are pleasant or repellent, sweet or savory and more flavors. Do they all belong to this category? A: We will first distinguish between taste and smell (sometimes there is a connection between the two senses). Flavorings are mainly related to food. The pheromones are odorants and we will focus on them. There are indeed different groups of such substances, but we will distinguish between chemicals used by individuals of the same biological species and those used for communication between individuals of different species. The chemicals in the second group are called allelochemicals and we will not deal with them in this article. The chemicals in the first group are pheromones [1]. These are a secreted or excreted chemical factor that triggers a social response in members of the same species, resulting in a change in their development or behavior. The term pheromone derives from two Greek words: pherein - to carry, and hormone.

Q: I see that the word hormone appears in the concept of pheromone. What is the connection?

A: Both pheromones and hormones are chemical "messengers", that is, secretions that transmit information or instructions to living systems. However, the hormones are in vivo communicating substances, that is, between organs in the same living body, while the pheromones are in vitro communicating substances, between different individuals of the same biological species.

Q: You consistently mention pheromones in the plural. What is the reason for this?

A: The information that needs to be transferred between individuals is vast and diverse, and in order to distinguish between types of information and their purpose, there is a need for a number of pheromones, different from one another, to transfer the appropriate information for a particular action. We define pheromones in various roles, for example:

Alarm pheromone - warns individuals in the population of imminent danger;

Aggregation pheromone - gathers the whole population (males and females) together whether for roaming (like locusts) or for finding food;

Territory pheromone - marks a living area (most commonly found in mammals, such as dogs and large carnivores);

Sex pheromone - attracts a mate for mating and fertilization purposes. This pheromone, which is most essential for biological existence, is mistakenly considered by many to be the same as all pheromones, and the predominant view is that pheromones are just sex pheromones. Of course, this is not true. We will return to the topic of pheromone specificity, in general, and the sex pheromone in particular.

Trail pheromone - marking a trail for various purposes, for example, by ants transporting food to the nest, or when roaming from nest to nest.
Q: Wait, is that all or are there more pheromones?

A: As I mentioned, there are different and varied messages, so there are more pheromones such as the pheromone of home recognition, the pheromone to prevent laying of eggs, the queen's pheromone (in the hive, for example, to allow the queen to control all the thousands of workers), the pheromone for removing dead bodies (after battles between nests of termites or ants). Undoubtedly, there are other undiscovered pheromones.

Q: From what you say, one can understand that pheromones are used for chemical communication between animals. Does the entire animal kingdom use them?

A: Yes indeed. As we know today, not only animals but also algae use sexual contact materials for fertilization, as do bacteria and other microorganisms, fish, various sea creatures, insects, spiders, amphibians, reptiles, and of course mammals.

Q: Do you mean humans too?

A: Certainly, there is an effect of chemicals on our behavior, and there may even be a sex pheromone, but the issue is still not definitively "closed" and there are various opinions on the subject. The organ responsible for sensing the sex pheromone in the high mammalian olfactory system probably degenerates in humans, so what remains is a remnant of a system that may have worked in the past. Other senses probably play an important role in the sexual connection of humans. What is clear is that women living together (nuns, student dormitories) within a short period of time begin "coordinating" (synchronizing) their menstrual period (also found in mice). But, let us return to the subject of pheromones and their properties.

Q: Indeed, an impressive variety. Do all pheromones have the same or different chemical components?

A: This is one of the unique and interesting phenomena - the pheromone is usually a mixture of several substances in a relatively constant ratio (although not uniform between all individuals), and is unique to each species. That is, the number of different molecules, used as pheromone components in one species, could reach ten or even more in several of the pheromones mentioned above.

Q: You mention that there are different chemicals. Maybe you can give an example of pheromones?

A: The pheromone ingredients are very varied and include substances from different families ranging from saturated hydrocarbons, through unsaturated, chain or ring, long chain alcohols, their acetates, aldehydes, aromatic substances, heterocycles, amino acid esters, steroid derivatives, terpenes, short peptides, and more (see Scheme 1). 
Scheme 1. Examples of pheromones and their components

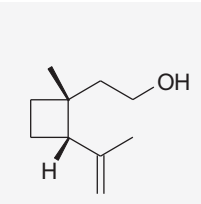

$(1 \mathrm{R}, 2 \mathrm{~S})-(+)-$-Grandisol Ratio: 6

Ratio: 6 (Anthonomous grandis).

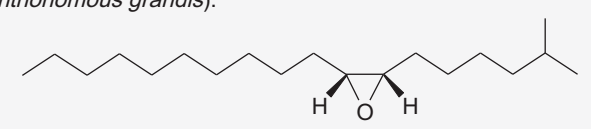

$(7 R, 8 S)-(+)$-cis-epoxy-2-methyloctadecane

Disparlure, sex pheromone released by the female gypsy moth (Lymantria dispar).

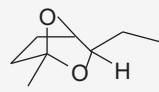

(1R,5S,7R)-(+)-exo-brevicomin

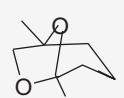

(1S,5R)-(-)-frontalin
Aggregation pheromone of the western pine beetle (Dendroctonus brevicomis) released by females (brevicomin), males (frontalin) and the tree (Myrcene).

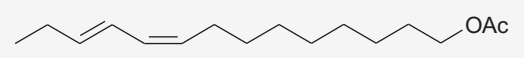

(Z,E)-9,11-tetradecadienyl acetate

Prodlure, the main component of the sex pheromone released by the female Egyptian cotton leafworm (Spodoptera littoralis).

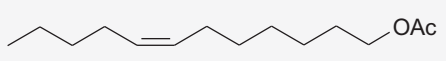

(Z)-7-Dodecenyl acetate

The sex pheromone released by the female Asian elephant

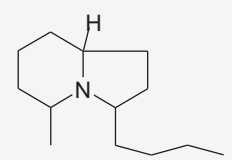

all-cis-5-methyl-3-butyloctahydroindolizine

Monomorine I, a component of trail pheromone released by Pharaoh's ant (Monomarium pharonis) and related species.

Q: What else characterizes pheromones?

A: The most important feature is its uniqueness - that is, each biological species has its own pheromones, and they usually do not interfere with or affect other species. This is extremely important in the sex pheromone, to prevent the attraction of mates between different, but closely related species, which could lead to unwanted hybridization. Unlike chemistry, which prefers hybrid orbitals, biology doesn't like hybrids of different species. Thus, even closely related species have their own unique pheromones. This can be seen in Table. 1, where we list the composition of sex pheromones of closely related species. The structure of the chemicals also shows us which molecules are commonly found in the pheromones of moths, which are devastating pests in agriculture.

Q: If you are mentioning agriculture, what are the major pests?
A: Food crops, industrial crops (cotton), forests for the timber industry - all of these are severely affected by moths (night butterflies), beetles and flies. It is estimated that about one-third of the crop is damaged in the field, and another $10 \%$ is damaged in harvesting, packaging and marketing, so that almost half the crops are damaged before reaching the consumer. From now on, I will concentrate on moths and their sex pheromones.

Table 1. Different relative composition of sex pheromones in closely related moth species

\section{Relative components of the pheromone}

\begin{tabular}{|c|c|c|c|c|}
\hline $\begin{array}{l}\text { The biological } \\
\text { species }\end{array}$ & $\begin{array}{l}\text { cis-11- } \\
\mathrm{C}_{14} \mathrm{OAc}\end{array}$ & $\begin{array}{c}\text { trans-11- } \\
\mathrm{C}_{14} \mathrm{OAc}\end{array}$ & $\begin{array}{l}\text { cis-9- } \\
\mathrm{C}_{14} \mathrm{OAC}\end{array}$ & $\mathrm{C}_{12} \mathrm{OAC}$ \\
\hline Archips agryrospilus & 60 & 40 & 4 & 200 \\
\hline \multirow[t]{2}{*}{ Archips mortaunus } & 90 & 10 & 1 & 200 \\
\hline & \multicolumn{2}{|c|}{ (cis,cis) $-7,11-\mathrm{C}_{16} \mathrm{OAC}$} & \multicolumn{2}{|c|}{$\begin{array}{c}\text { (cis,trans)-7,11- } \\
\mathrm{C}_{16} \mathrm{OAc}\end{array}$} \\
\hline $\begin{array}{l}\text { Pectinophora } \\
\text { gossypiella }\end{array}$ & \multicolumn{2}{|c|}{1} & \multicolumn{2}{|c|}{1} \\
\hline Pectinophora endema & \multicolumn{2}{|r|}{1} & \multicolumn{2}{|c|}{0.5} \\
\hline $\begin{array}{l}\text { Pectinophora } \\
\text { scutigera }\end{array}$ & \multicolumn{2}{|r|}{1} & \multicolumn{2}{|c|}{0.1} \\
\hline
\end{tabular}

Q: Why moths?

A: For several reasons: First, the larvae of the moths are the most severe pests and they have developed significant resistance to conventional pesticides (organochlorines such as DDT), organophosphates (such as parathion), carbamates, pyrethroids, nicotinoids and more.

Second, sex pheromone components in moths belong to a well-defined and relatively easy group of chemicals: derivatives of fatty acids i.e., alcohols with a chain length of 10 to 18 carbon atoms with one, two or three double bonds in cis and trans configurations at different locations along the chain length, and acetates and aldehydes derived from these alcohols. There are of course other derivatives, such as epoxides. Third, it is relatively easy to grow these insects in the laboratory, enabling continuous research throughout the year. For these reasons, it is clear why the number of pheromones currently identified is mainly in this group of insects. If, in the early 1960s (when pheromone research first become popular), the structure and composition of pheromones of only a few moths was known, today more than a thousand are known.

Q: What else can be said about moth sex pheromones?

A: Beyond their uniqueness, their high sensitivity is next in line. Controlled laboratory experiments show that the amount required for a male moth to start looking for a female moth, 
which secretes the sex pheromone, is about $10^{-18}$ grams per cubic centimeter, which is a few thousand molecules, enough to stimulate the male to sexual attraction and looking for the female. The pheromone produced in the female moth gland turns out to be in the range of nanograms or less. Table 2 summarizes some quantitative data.

Table 2. Quantities of sex pheromone isolated from female moths

\begin{tabular}{|l|c|c|c|}
\hline Biological Species & No. of females & Extracted $(\mathrm{mg})$ & $\mathrm{ng} / \mathrm{female}$ \\
\hline Almond moth & $1,200,000$ & 6.1 & 5.08 \\
\hline Indian meal moth & 335,000 & 0.5 & 1.49 \\
\hline $\begin{array}{l}\text { Mediterranean } \\
\text { flour moth }\end{array}$ & 283,000 & 0.8 & 2.83 \\
\hline Tobacco moth & 1,313 & 0.0024 & 1.83 \\
\hline
\end{tabular}

The enormous differences in the biological activity of the silkworm moth pheromone isomer series, shown in Table 3, demonstrate the high specificity of the pheromone structure.

Table 3. Comparative attraction of sex pheromone in silkworm moth and its isomers

\begin{tabular}{|l|c|}
\hline Tested isomer & Attractivity $(\mu \mathrm{g} / \mathrm{ml})$ \\
\hline $\begin{array}{l}\text { Natural pheromone (trans-10, cis-12- } \\
\text { hexadecadienol) }\end{array}$ & $10^{-10}$ \\
\hline Cis-10, cis-12-hexadecadienol & 1 \\
\hline Cis-10, trans-12-hexadecadienol & $10^{-3}$ \\
\hline Trans-10, cis-12-hexadecadienol (synthetic) & $10^{-12}$ \\
\hline Trans-10, trans-12-hexadecadienol & 100 \\
\hline
\end{tabular}

Scheme 2 further illustrates the uniqueness of the structure and its effect on biological activity. Extending the hydrocarbon chain by one carbon atom, moving the double bond, changing from cis to trans, or changing the ester group - all severely impair biological activity.

Scheme 2. Comparing activity (quality) - male attraction of red banded leaf roller moth to different chemicals

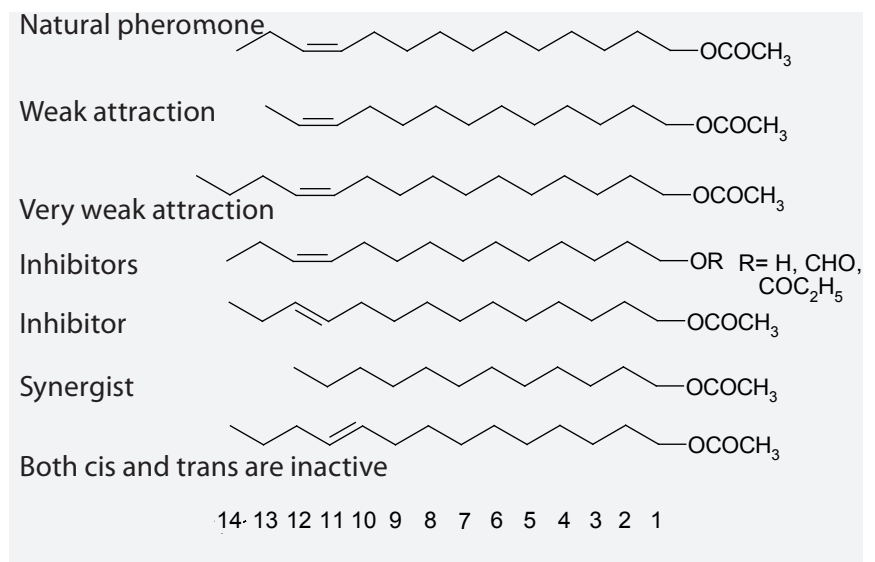

These tiny quantities, which are actually a mixture of a few ingredients, made it difficult to research pheromones at the beginning. The idea of volatile chemicals being used for remote sexual attraction among insects was already known in the 1930s, when moth females in traps were used in Czechoslovakia to attract and detect the harmful moths: the males were attracted to the females so that the farmers knew if the pest was actually in the plantation or in the field, and, if so, in what quantity and in what areas. This method - the monitoring method - is currently widely used in areas of vegetables, cotton fields, orchards, forests and other crops.

Q: Why did you note that "these tiny quantities made it difficult for pheromone research to get started"?

A: It was not until the 1960s that gas chromatography became practical and widely used in organic chemistry research. Sensitivity was then low and relatively high concentrations were required but, nonetheless, micrograms concentrations could be detected. It was only in the 1980 s that the nanogram (or even less) sensitive devices began to appear. In 1988, I measured quantities of pheromone components from one female moth gland that reached $20-50$ picograms $\left(10^{-12}\right.$ grams).

Q: I'm sorry to interrupt you, but from when are the pheromones known?

A: Only briefly, because I do not want to deviate from the main topic. Well, in the 17th century scientists investigated the behavior of ants and noticed the well-known phenomenon of walking in a food-gathering column, or moving from nest to nest, for example, and assumed that there were components that allow ants to follow one another. Another finding was reported in the 1870 s by the French pastor Faber, whose hobby was butterfly breeding. He showed that the antenna of the butterfly is the "smelling" organ and that males are attracted to females for mating. The scientific report on the first identified pheromone, a sex pheromone of the silkworm moth, the silkworm we raised on mulberry leaves when we were children, was published in 1959. Since then, there has been a real surge in pheromone research, ranging from the isolation and characterization of the pheromone components, their synthesis to prove structure and application requirements, studying the pheromone biosynthesis process based on the genetic and hormonal control of the process, the sensing of the pheromone in the antenna and the electrophysiological processes derived from it, the enzymatic metabolism and exclusion of the products from the receptors, and a simple way to apply pheromones in pest control, and all that entails. In these studies, biologists, chemists, ecologists, pesticides production and farmers are all involved.

Q: You mentioned the use of pheromones for pest monitoring purposes. What exactly do the traps trap? 
A: Before answering your question, just a short explanation: As you know, insects usually have four stages in their life cycle: egg, caterpillar, pupa and adult. Such a cycle can be seen in the series of pictures of the beetle Meladera matrida, known in Israel as "Khomeini", which is a species new to science (Figure 1). Usually, the adult is responsible for fertilization and reproduction, so the sex pheromone is secreted by the adult (male or female) to attract the other mate. By monitoring the population of the adult of the specific pest (ensnaring the adults by attracting them with the sex pheromone in traps), one can get crucial information about the size of its population, its spreading in the field and when to treat it. This information answers the big $\mathrm{W}$ questions: When, Where, What and hoW much to spray of the pesticide.

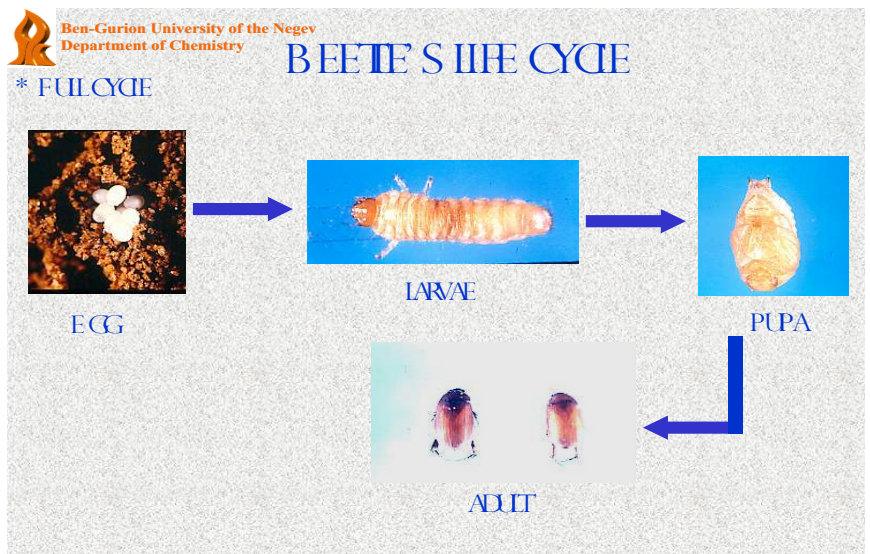

Figure 1. The life cycle of the beetle Maldera matrida, a new species to science discovered in Israel

Q: How does the adult moth find its mate?

A: A change in the amount or concentration of pheromone in the air enables the moth to locate the pheromone source. A female moth that secretes the sex pheromone protrudes from the end of her abdomen (where the tiny pheromone gland is located, sub-mm in size, which produces and secretes the pheromone), so that wind and air currents absorb the pheromone components and transport them. Using the antenna, the pheromone molecules are detected and the male begins to fly upwind, against the airflow, and feels a growing concentration of pheromone in the air. To make sure, they fly in a zig-zag track, and sense the concentration changes in the air at varying altitudes. One can describe this flight as conical with the apex pointing at the source, where the pheromone originated, tens and hundreds of meters away. In this way, they navigate their path until they reach the source and find the female calling them.

Q: If I understood correctly, disruption of the pheromone concentration in air could interfere with the male locating the female.
A: Great point. Indeed, the effective way of damaging the chemical communication between males and females is by artificial "saturation", relative to the pheromone concentration in the air. I shall come to this later.

Q: Is that why both the first and the second titles of the article are as shown above?

A: Indeed, it is. The component of sex life is already clear, and the economic component stems from the fact that pesticides to control insects (insecticides) are used every year at a cost of $\$ 8-10$ billion. Millions of tons of these materials are sprayed in fields, orchards and forests each year. We breathe and eat these harmful pesticides that contaminate the environment, harm natural enemies and beneficial insects, and undermine biological equilibrium. Most of all, the pests develop resistance to these insecticides. This resistance reduces the effectiveness of the materials, necessitating a constant search for new and effective materials (in many cases toxicity also increases). This open-ended research process requires the investment of hundreds of millions of dollars to introduce one new pesticide into the market after ten years of research and examination of about 15,000 new chemicals. The result is that the number of new chemicals entering the field every year is decreasing. In addition, governments and environmental authorities mandate a reduction in the use of toxic pesticides. These have all led to the advanced approach of integrated pest management (IPM), or integrated protection, which employs all means to protect the crop from pests. In this power game, the pheromones have a wide range of possible applications, and some of them are already in use.

Q: It is now clear to me that there is no advertising trick here and there is a reason for every word. We will now return to the pheromone topic. You cited the "confusion" method as a way of pest control. Can you expand?

A: Remember, the male locates the calling female according to the change of concentrations in the air. If we create a state in which the concentration in the air is uniform and constant, and higher than the natural concentration that results from its spread by the female (as established in moths), the males will not be able to locate the pheromone source and will not know where to fly and look for the females.

Q: It sounds very simple.

A: True, like many ingenious things that are simple, so is "confusion." Properly applying and releasing enough sex pheromone of a specific moth, seems to prevent sexual encounter between the mates, and the level of interference in communication reaches about 98-99\%, which means almost complete prevention of fertilization. The result is that the amount of fertilized eggs laid in the field is extremely low and the level of pest population in the next generation is extremely low, and the level of damage to the crop is low as 
well. This allows the farmer not to spray pesticides (or very little), because the expense of spraying is higher than the damage caused by the pest.

Q: That sounds nice, but what is the cost of applying the pheromone preparation in the field?

A: Calculations and actual testing by the farmers show that the cost of the pheromone preparations is the same as the cost of pesticides, so it is economically worthwhile. In addition, there are farmers who are interested in organic farming, without using pesticides, even if the cost is higher, because the value of "green" produce is higher. Thus, from every angle, the method is affordable. If we add the environmental aspects then it is important to apply pheromones in pest control.

Q: Are there any other benefits of pheromones that you don't mention?

A: The most convenient way is to present the properties of the pheromones versus those of conventional chemical pesticides, as we see in Table 4. If we go through each section, individually, we can find the benefits and differences and answer them.

Table 4. Characteristics of pest control based on insect sex pheromone compared with conventional insecticides

\begin{tabular}{|l|l|}
\hline Pheromones & Insecticides \\
\hline $\begin{array}{l}\text { Selectively eliminate harmful } \\
\text { insects }\end{array}$ & $\begin{array}{l}\text { Eliminate insects non- } \\
\text { selectively }\end{array}$ \\
\hline $\begin{array}{l}\text { Do not disrupt biological } \\
\text { equilibrium } \\
\text { (partial elimination) }\end{array}$ & $\begin{array}{l}\text { Disrupt biological equilibrium } \\
\text { (eliminate most insects) }\end{array}$ \\
\hline $\begin{array}{l}\text { Do not pollute the } \\
\text { environment }\end{array}$ & $\begin{array}{l}\text { Cause severe environmental } \\
\text { pollution }\end{array}$ \\
\hline Nontoxic & Toxic to man and other animals \\
\hline $\begin{array}{l}\text { Unstable, decompose in the } \\
\text { field }\end{array}$ & Some are extremely stable \\
\hline $\begin{array}{l}\text { No resistance mechanism } \\
\text { observed since this would lead } \\
\text { to suicide. Insects may develop } \\
\text { evasion. }\end{array}$ & $\begin{array}{l}\text { Lead to development of } \\
\text { resistance }\end{array}$ \\
\hline $\begin{array}{l}\text { Minute amounts required; } \\
\text { dose for attraction of a single } \\
\text { insect } 10^{-18}-10^{-15} \mathrm{~g}\end{array}$ & $\begin{array}{l}\text { Very large amounts needed; } \\
\text { dose for elimination of a single } \\
\text { insect } 10^{-6} \mathrm{~g}\end{array}$ \\
\hline $\begin{array}{l}\text { Development moderately } \\
\text { expensive }\end{array}$ & Development very costly \\
\hline
\end{tabular}

Q: I see that you indicate that "resistance" is unlikely to develop and emphasize that this is a "suicide" act. What does that mean?

A: In order to explain the topic, which is very basic in science, it is necessary to understand that the resistance to sex pheromones means that no attraction between the mates will occur. Instead, the insects will find a way to evade the effect of "excess" pheromones. We know that every action in nature draws a response, not only in physics but also in all life processes and environmental factors.

If we focus on pesticides for insect control (including antibacterial and drugs included in this explanation), which are actually poisonous substances to the living organism, we know that over the years (usually within 5-6 years), a pest population develops resistance and is no longer affected by the pesticide. The process or mechanism employed is based on the insect's biochemical-enzyme ability to neutralize pesticides or remove them from its body before experiencing its toxic action. This property, which is the result of an organism's individual mutation, is passed on to future generations, thus developing a poison-resistant population. In other words, the living body fights the external poisonous chemicals and prevents its destructive activity. This is natural selection in which individuals survive by adapting to changing environmental conditions.

Unlike all pesticide and other pest-control approaches, pheromones are essential ingredients for animals, in general, and insects in particular. Most important of all is the sex pheromone, without which there is no sexual mating between the mates, no fertilization and no next generation. Therefore, no resistance to the pheromone can develop. The reaction would probably consist of evading the impossibility of chemical communication by interfering with communication - mating disruption ("confusion"). In other words, by "confusion" we will cause the insects to try to "call" the other mate, but "look for" mechanisms to overcome the communication problem.

I propose to call this process evasion (rather than resistance), because there is no resistance here in the conventional sense of the word, as described above, so the different processes must be distinguished.

Q: What does this mean in terms of chemistry and biology? A: We know that pheromones are usually a mixture of chemicals and the amount produced by the female is in nanograms. That is, there are two noteworthy factors here the quantity and the quality, that is, the amount of pheromone produced by the female and/or the relative composition of the pheromone components.

Q: Do you mean to say that females can affect quantity and quality?

A: In principle yes, although not consciously, of course. We know that there is no complete uniformity in the quantity and composition of the pheromone among all females of the same 
species. Moreover, different populations of the same biological species, located in different regions of the world, have different compositions, yet are still capable of transmitting genetic properties and reproduction. This situation can be seen as the beginning of the emergence of new species - speciation - a gradual variation in the pheromone composition, which will eventually lead to the termination of chemical linkage between the mates in the different populations, hence the termination of fertilization and the transmission of genetic code. This is the result of geographical isolation, which is known as a major cause for the emergence of new species.

Q: What's the connection of these things to our topic?

A: The connection is close as we can see right away. Remember, the "confusion" method is based on atmospheric saturation (relative to the natural concentration, of course) in the pheromone, so that the uniformity of the pheromone concentration in the air prevents the males from locating the females. Because the amount of pheromone distributed into the air differs among the females, the few females that release a large amount of pheromone into the air have a better chance of being the focus of attraction for males. If those females manage to mate (and we know that there is a certain percentage of success despite the "confusion") the ability to produce more pheromone will pass on their hereditary daughters, and granddaughters and future generations. That is, the "confusion" will cause an increase in the amount of pheromone in the population, as a first step to the pressure we exert on the insect through the pheromone and interference in the chemical communication.

Q: Can this be proven?

A: One way is to check a field where the confusion method was applied and see what happens. Indeed, in cotton fields in the United States, after the "confusion" of the pink bollworm moth (Pectinophora gossypiella) that lasted for 4 years, a 25\% increase in pheromone production in females was found. This period corresponds to about $8-10$ generations of the moth. A second way is to perform a lab experiment, despite the great differences between lab and field conditions.

Q: And what did you find?

A: After 7-8 generations of "confusion" in the laboratory, the amount of pheromone in females of a confused population was doubled compared to a normal population used as a control. This is clear proof that the "confusion" resulted in a natural selection of those females producing a higher titer of pheromone, while all those poor in pheromone failed to attract males and did not produce offspring. This is an example of the indirect evasion phenomenon mentioned above. There is no resistance here in the common sense, but evasion of the new situation encountered by the confused population. This was the first lab experiment of its kind in the world that demonstrated the possibility of evasion of confusion in terms of quantity [2].

Q: And what about the pheromone composition?

A: Here is my working hypothesis. The composition of the pheromone in the population differs among females and, for simplicity, we will focus on the case where there are only two components of the pheromone, and the composition varies in the population. This is described schematically in Figure 2a. The composition applied in the field in confusion is the average composition of the population, and the males are affected and cannot locate the females that release the average composition (Figure 2b). Females with a pheromone composition significantly different from the average composition can still attract those males that respond to these compositions (Figure 2c). Of course, it could be that the average new composition will shift to one side or another without separation to two populations.

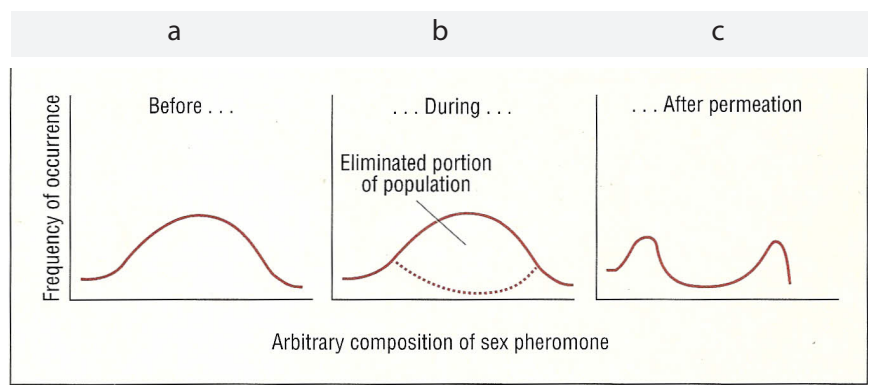

Figure 2. Schematic description of "confusion" in an insect population that produces a pheromone consisting of two pheromone components and a wide distribution of pheromone composition in the population. The possible result is the elimination of most of the population that responds to the average composition of pheromone applied to confusion and the development of marginalized populations, whose pheromone composition differs significantly from the original composition. Communication in these populations will be weakened considerably, resulting in two subspecies and then two new, though closely related, reproduction isolated species. This process is chemospeciation, which means speciation (appearance of new species) under the influence of chemicals.

Q: Sorry, if the composition is significantly different from the average composition, how do the males react?

A: Here it should be emphasized that there must be a match between the males and females regarding the chemical signal transmitted: if the composition is unmatched, chemical contact will stop and be damaged. Therefore, information regarding any change in the composition that the female produces and releases into the air must be transmitted to males (presumably this is done by way of inheritance from parents). In other words, just as females have a wide range of composition, so males have a wide range of sensors to 
recognize and react to this composition. Therefore, only a few males will be able to locate these females, but this is enough to start a process of forming different populations. We see two minor populations present in the original population (Figure 2b). But since there is no vacuum in nature, the drastic reduction in the harmful population will allow these minor populations to develop and reproduce. These groups, as in the case of the geographic isolation I mentioned above, rarely "chat" between them, and their sexual attraction will weaken and disappear. The lack of a sexual encounter means no reproduction, and all that this implies, namely, the emergence of new species. This situation is shown in Figure 2 c. I call this process chemospeciation, namely speciation under the influence of chemical factors. One point should be emphasized: The treated area should be large enough and, most important, isolated from other fields to eliminate any gravid females entering and adding more damaging larva and thus negatively affecting the mating disruption.

Q: Indeed, an interesting theory, involving work that is innovative. But is it true? Is there evidence of such a process? A: In the experiments I performed above, while measuring the amount of pheromone produced by each female individually, I also tested the pheromone composition, but found no change in it. Also, in the field trial, with pink bollworm moth in cotton fields, which I mentioned earlier (25\% increase in the amount of pheromone), no change was found in the composition.

Q: What does the composition mean?

A: It means the relative composition, that is, the ratio of pheromone components and this can vary. For example, in the case of two components, an average ratio of 3:1 could also be 2: 1 or 1: 1. If we look at data in Table 1, such differences do indeed appear to exist in nature between closely related species. The more complex process there will be removing or adding a new component to the pheromone. As mentioned above, only males who have inherited the composition information will be able to sense the new composition and locate the females distributing it.

\section{Q: Is such a process possible?}

A: From looking at the processes in nature we see that changes occur, and there is no doubt that the proposed process occurs by mutations and natural selection. It turns out that there are rare genes that can be expressed and cause "quantum jumps" in the traits. For example, in the case of a gene recently reported to be responsible for producing a pheromone composition different from the average composition established in the particular moth, this occurred by the addition of another isomer to the pheromone composition. This is an example of being in the same area, without geographical isolation, and is called sympatric speciation, a process whose existence in nature has been demonstrated many times, contrary to what was thought in the not too distant past.

Q: The basic biological meaning is clear, but what does it mean for pest control?

A: The result of the evasion process, whether by increasing the amount of pheromone distributed by the females or by a change in the composition, can immediately be traced. We can determine what is changing and act accordingly. If only the quantity is increasing, we can distribute a greater amount of pheromone in the field leading to more effective masking. To determine if the composition has changed, females can be collected from the field and their pheromone composition checked, either as an average or in individual cases, to see what changes have occurred. We can then immediately implement the new composition. Such a test can take several months to a year, resulting in an improved product that can fulfill its purpose in a short period of time. There is no need to synthesize thousands of new materials and test their effectiveness, on the one hand, and we will continue to keep reducing rates and their detrimental effect on animals and the environment, on the other. Thus, in the constant and incessant battle between humans and harmful insects, we will gain the upper hand, always one step ahead to prevent damage to agricultural crops and reduce ecological damage. So far, the "insect's hand" is on top.

Q: In conclusion, how do you apply these devices for interfering with the insect and "confusing" the insects in the field?

A: For over 30 years, since the pheromones began to be used for "confusion", all the devices are applied manually, whether it is a polyethylene lanyard containing the pheromone, which is released slowly through the cover, or vials, acting in the same manner, multi-layer polymeric preparations, and the like. Characteristic of all these is the need for much manpower during the short period of manual application. This is possible in a small plantation or field area, but not suitable for large areas of tens of thousands of acres or forests. What is needed is a product for the slow release of pheromones that can be sprayed from conventional spray equipment, whether tractor or airplane, and is active in the field for several weeks. So far, unfortunately, there is no such product on the market, mainly because of the high volatility of the pheromones released over a short time. Thus, the efficacy of the slow-release device is not sufficient to control insect pests in fruits and vegetables for human consumption. Cotton is now genetically modified and most cotton fields are planted with resistant plants with almost no damage caused by the main pests.

Q: What does this mean for the future?

A: The hope is that in the future, farmers and foresters will not use conventional pesticides at the outset, but will combine 
agrotechnical methods with biological pest control methods using natural enemies and parasites, mating disruption with pheromones. They will only use pesticides as a last resort. In this way, resistance toward pesticides will be slowed down, the negative impact on the environment will be reduced, consumers will get products free (or almost free) of pesticides and the farmer can earn a living from his investment in producing the various types of agricultural products.

Q: Thanks for the detailed explanations.

A: Thank you for your interest and, if there are any further questions, I would be happy to answer.

\section{New developments}

Since retiring, I do not run active research, but follow the literature to see what other scientists do and learn from them. A short time ago, I found a paper [3] by authors from the Volcani Center, Israel, and Iowa State University. There I found what I had long been looking for - a report on mating disruption application with pheromones in the pink bollworm moth (Pectinophora gossypiella, Figure 3 ) and the appearance of a change in pheromone composition, as I forecasted years ago. The paper describes a change in the sex pheromone, which is a 1:1 mixture of two isomers (mentioned above in Table 1) to 62:38, which is not as effective as the natural one. One should notice that this happened after some thirty years of mating disruption of the pest in all cotton fields in Israel with no other cotton fields in the vicinity. As there are 4-5 generations per year, it means that at least 120 generations passed before the evasion took place.

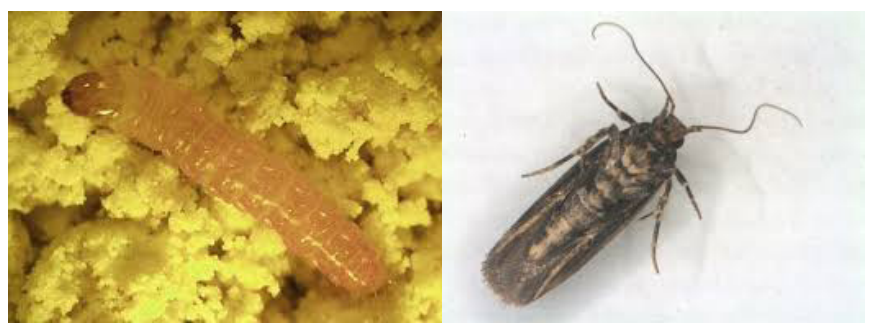

Figure 3. Left: larva of the pink bollworm moth. Right, adult of the pink bollworm moth

My argument is that the "new" composition was already in the native population and it appeared after eliminating the majority of the native one. The claim that a change is in the genetics caused the change in composition seems unreasonable to me: why "create" something new, when it already exists in the population. The problem is that there is no population profile of the natural pheromone before the mating disruption mode started. Today there are no such insects in Israel. The only way to find out is to get native population from other fields, with the hope that the population there is really representative of the original population and pheromone composition. In any case, to tell the truth, I did not expect to see my hypothesis come true in my lifetime!

I wish you good reading. My articles dealing with pheromone collecting from live individual females are in Refs. [4-9].

\section{References}

1. J. D. Allison and R. T. Carde eds., Pheromone Communication in Moths, U. California Press, 2016.

2. A. Shani and J. Clearwater, "Evasion of mating disruption in Ephestia cautella (Walker) by increased pheromone production relative to that of undisrupted populations," J. Stored Prod. Res. 2001, 37, 237-252.

3. X. Dou, S. Liu, V. Soroker, A. Harari and R. Jurenka, "Pheromone gland transcriptome of the pink bollworm moth, Pectinophora gossypiella: Comparison between a laboratory and field population,” PLoS ONE, 2019, 14, e0220187.

4. A. Shani and M. J. Lacey, "Convenient method applicable to single insects for collection and measurement of blend ratios of airborne pheromones from artificial sources," J. Chem. Ecol. 1984, 10, 1677-1692.

5. P. B. Barrer, M. J. Lacey and A. Shani, "Variation in relative quantities of airborne sex pheromone components from individual females Ephestia cautella (Lepidoptera:Pyralidae)," J. Chem. Ecol. 1987, 13, 639-653.

6. A. Shani, "Calling behavior of single almond moth (Ephestia cautella) females kept in glass cages and airborne pheromone deposited on glass surfaces by air stream," J. Chem. Ecol. 1990, 16, 959-969.

7. A. Shani, "Air Sampling of volatile sex pheromone components in a closed jar," J. Chem. Ecol. 1990, 16, 971-980.

8. A. Shani and J. Clearwater, "How efficient are all-glass systems for the collection of airborne," J. Chem. Ecol. 1997, 23, 1621-1633.

9. A. Shani, "Pheromones as a key element in integrated pest management,"CHEMTECH, 1998, 28, 30-35. 